Article

\title{
4-Unit Molar Fixed Partial Dentures Made from Highly Translucent and Multilayer Zirconia Materials: An In Vitro Investigation
}

\author{
Thomas Strasser*, Alois Schmid (D), Christina Huber (D) and Martin Rosentritt (D)
}

check for

updates

Citation: Strasser, T.; Schmid, A.;

Huber, C.; Rosentritt, M. 4-Unit

Molar Fixed Partial Dentures Made from Highly Translucent and Multilayer Zirconia Materials: An In Vitro Investigation. Ceramics 2022, 5, 99-107. https://doi.org/10.3390/ ceramics5010009

Academic Editors: Frank Kern, Andraz Kocjan, Ángela Gallardo-López and Gilbert Fantozzi

Received: 18 January 2022

Accepted: 1 February 2022

Published: 8 February 2022

Publisher's Note: MDPI stays neutral with regard to jurisdictional claims in published maps and institutional affiliations.

Copyright: (C) 2022 by the authors. Licensee MDPI, Basel, Switzerland. This article is an open access article distributed under the terms and conditions of the Creative Commons Attribution (CC BY) license (https:// creativecommons.org/licenses/by/ $4.0 /)$.

\author{
Department of Prosthetic Dentistry, UKR University Hospital Regensburg, 93042 Regensburg, Germany \\ alois.schmid@ukr.de (A.S.); christina.huber@ukr.de (C.H.); martin.rosentritt@ukr.de (M.R.) \\ * Correspondence: thomas.strasser@ukr.de
}

\begin{abstract}
Background: Modern zirconia blanks for the fabrication of dental CAD/CAM restorations provide a layer structure with color and strength transitions. Variation in the yttria content has a particular effect on the characteristics of the materials. The properties of dental restorations may vary depending on the milling position within the blank. Especially for wide-span fixed partial dentures (FPDs), relevant effects on clinical performance might result. This study investigated if the application of high-translucent zirconia and positioning within multilayer zirconia blanks affect the in vitro performance of 4-unit FPDs. Methods: 4-unit FPDs were fabricated from monolayer 3Y-TZP-A, 3Y-TZP, 4Y-TZP, 5Y-TZP, 4Y /5Y-TZP, and different positions within multilayer zirconia blanks (3Y-TZP/5Y-TZP). The FPDs were adhesively luted to resin abutment teeth, divided into groups ( $n=8$ each): "baseline" ( $24 \mathrm{~h}$ water-storage)/“TCML" (chewing simulation by means of thermalcycling and mechanical loading), and loaded to fracture. The statistics included mean and standard deviation, one-way ANOVA, Bonferroni post hoc test, and Pearson correlation $(\alpha=0.05)$. Results: The mean fracture force values varied between $803.8 \pm 171.7 \mathrm{~N}(5 \mathrm{Y})$ and $1474.1 \pm 193.0 \mathrm{~N}$ (3Y) (baseline) and 713.5 $\pm 190.9 \mathrm{~N}$ (5Y) and 1337.4 $\pm 205.6 \mathrm{~N}$ (3Y) (TCML). Significantly different $(p=0.000)$ results between the groups and individual significant differences $(p \leq 0.039)$ were found. Conclusions: Positioning within multilayer blanks affected the fracture force only slightly. Multilayer, 3Y-TZP-A, 3Y-TZP, and 4Y-TZP seem appropriate for the clinical application with 4-unit molar FPDs. Application of $5 \mathrm{Y}-\mathrm{TZP}$ is critical.
\end{abstract}

Keywords: zirconia; multilayer; 3Y-TZP-A; 3Y-TZP; 4Y-TZP; 5Y-TZP; FPD; fracture force; TCML; in vitro

\section{Introduction}

The implementation of monolithic ceramics is a preferred option in the fabrication of fixed partial dentures (FPDs) [1,2], but there is a need for more clinical evidence concerning the long-term performance of zirconia FPDs [3-5]. The range of new zirconia materials on offer is becoming increasingly complex for both dentists and dental technicians. Nevertheless, knowledge of the properties, appropriate application, and processing of different zirconia types is essential for choosing the correct indications and, ultimately, for clinical success.

The desire for esthetic monolithic restorations is a key aspect in the development of new zirconia materials [6]. The improvement of translucency is crucial here. However, the required compositional changes affect the crystal structure and have a significant impact on the mechanical properties of the materials [7-10]. The main distinguishing feature is the individual $\mathrm{Y}_{2} \mathrm{O}_{3}$ admixture. This varies between 3 and $5 \mathrm{~mol} \%$ according to the nomenclature 3Y-TZP/4Y-TZP/5Y-TZP for "tetragonal zirconia polycrystal" with the corresponding yttria content. In contrast to 3Y-TZP and 4Y-TZP, 5Y-TZP shows high proportions with a cubic lattice structure, which results in a higher translucency due to its larger grain size but also due to the isotropy of the lattice structure. However, in 
particular, 5Y-TZP materials are less mechanically stable than zirconia materials with lower yttria content [11]. Mixtures of different zirconia systems are conceivable, although their properties have not yet been investigated. Besides, materials, such as the investigated 3Y-TZP-A, show higher $\mathrm{Al}_{2} \mathrm{O}_{3}$ content compared to other Y-TZP materials, which leads to high mechanical strength but also to pronounced opacity [12]. Currently, 3Y-TZP is a clinically preferred material when tooth-colored; monolithic, wide-span restorations are to be fabricated. The question arises as to whether highly translucent zirconia materials can also withstand the masticatory forces in long-span FPDs in the posterior region.

In addition to the distinction between different classes of zirconia, there are more and more multilayer blanks. The layered structure of these blanks is intended to replicate the esthetics of natural teeth with a shift in shade and/or translucency from the incisal edge or cusp tips to the cervical portions while achieving high mechanical strength. Here, it is important to distinguish blanks that merely show a gradient of color from those that actually consist of several layers of different zirconia materials. The layered structure of these blanks is associated with the different material properties of the individual layers [13], and the interface between the individual layers could affect the mechanical properties of the produced restorations [14]. The typical layering of such blanks consists of a superficial highly translucent enamel layer of 5Y-TZP followed by a transition layer with a mixture of 5Y-TZP and 3Y-TZP and then an opaque layer of 3Y-TZP with higher mechanical strength. In addition, the thickness of the individual layers can vary from manufacturer to manufacturer and, therefore, have an influence on the properties of the restoration. Concerning multilayer zirconia, it has been shown that the position within the blank, from which the restorations are milled, may affect their mechanical properties [13,15].

The aim of this study was to compare the in vitro performance and fracture force of different zirconia materials when used for 4-unit molar FPDs. The hypotheses of this study were that the in vitro performance and fracture force of 4-unit FPDs is influenced by:

- $\quad$ the $\mathrm{Y}_{2} \mathrm{O}_{3}$-content (3Y-TZP, 4Y-TZP, 5Y-TZP),

- the $\mathrm{Al}_{2} \mathrm{O}_{3}$-content (3Y-TZP, 3Y-TZP-A),

- $\quad$ the composition (uniform mixture 4Y-TZP and 5Y-TZP), and

- $\quad$ the position of the FPD within different multilayer blanks (above 5Y-TZP/below 3Y-TZP).

\section{Materials and Methods}

Four-unit FPDs (FDI: 24 retainer crown, 25 pontic, 26 pontic, 27 retainer crown) were fabricated from different positions within the blanks of multilayer zirconia materials (3YTZP/5Y-TZP) as well as from 3Y-TZP-A, 3Y-TZP, 4Y-TZP, 5Y-TZP, and combined 4Y/5Y monolayer blanks (Table 1). Artificial molar teeth were milled from PMMA resin (CORiTEC Disc PMMA, Imes Icore, Eiterfeld, Germany). Preparation design was chosen meeting the requirements for ceramic restorations (no sharp angles or edges; shoulder preparation with rounded inner edges; at least $1.0 \mathrm{~mm}$ material thickness; preparation height at least $4 \mathrm{~mm}$; preparation angle $4-8^{\circ} ; 9 \mathrm{~mm}^{2}$ minimum connector strength; rounded basal connector areas). For simulation of periodontal resilience, the roots were covered in polyether impression material (Impregum, 3M Espe AG, Seefeld, Germany) and then embedded in a resin base with a $19 \mathrm{~mm}$ gap in between. The artificial teeth were sandblasted $\left(\mathrm{Al}_{2} \mathrm{O}_{3}\right.$, $100 \mu \mathrm{m}, 1 \mathrm{bar}$ ) and the FPDs were adhesively luted to the teeth according to the manufacturer's instructions (Panavia F2.0 TC, Kuraray Noritake, Japan). Specimens were divided into two groups, "baseline" and "TCML" ( $n=8$ each). Control group "baseline" was

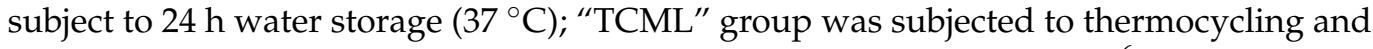
mechanical loading $\left(2 \times 3000 \times 5{ }^{\circ} \mathrm{C} / 55^{\circ} \mathrm{C}, 2 \mathrm{~min}, \mathrm{H}_{2} \mathrm{O}\right.$ dist., $1.2 \times 10^{6}$ á $50 \mathrm{~N}, 1.6 \mathrm{~Hz}$, $1.5 \mathrm{~mm}$ lift). A steatite ball (diameter: $10 \mathrm{~mm}$ ) served as central antagonist. During TCML, the specimens were monitored for defects. Damaged FPDs were excluded from further testing. Subsequent to TCML, fracture force was determined by central loading at the pontic teeth (steel ball diameter $12 \mathrm{~mm}$, tin foil; speed: $1 \mathrm{~mm} / \mathrm{min}$; Zwick Z010, Zwick, Ulm, Germany). Means and standard deviations were calculated, one-way ANOVA and 
Bonferroni post hoc tests were performed, Pearson correlation of fracture force and flexural strength (manufacturers' information) were determined with the level of significance set to $\alpha=0.05$ (SPSS $/$ PC + software 26.0, IBM, Armonk, New York, USA). Fractured FDPs were analyzed according to the location of fracture, and fracture surfaces were investigated to localize the cause of the failure $(20 \times-2000 \times$; VHX-microscope, Keyence, Osaka, Japan).

Table 1. Materials, manufacturers' specifications, sintering procedure.

\begin{tabular}{|c|c|c|c|c|c|c|c|c|}
\hline Group & Material & Layer & $\begin{array}{l}\text { Zirconia } \\
\text { Type }\end{array}$ & $\begin{array}{c}\text { Flexural } \\
\text { Strength } \\
\text { [MPa] }\end{array}$ & $\begin{array}{c}\text { Translucence } \\
\%\end{array}$ & $\begin{array}{c}\text { Layer } \\
\text { Thickness } \\
\text { [mm] }\end{array}$ & $\begin{array}{c}\text { Blank } \\
\text { Thickness } \\
\text { [mm] }\end{array}$ & $\begin{array}{l}\text { Sintering } \\
\text { Procedure }\end{array}$ \\
\hline \multirow{2}{*}{ ML5/3 1 a } & \multirow{3}{*}{$\begin{array}{c}\text { IPS e.max } \\
\text { ZirCAD Prime * }\end{array}$} & top & $5 Y$ & 650 & 49 & 3 & & \\
\hline & & middle & $3 Y / 5 Y$ & $1200 / 650$ & $40 / 49$ & 4 & 16 & 1 \\
\hline ML5/3 1b & & bottom & $3 Y$ & 1200 & 40 & 9 & & \\
\hline ML5/3 2 a & \multirow{3}{*}{$\begin{array}{l}\text { priti multidisc } \\
\mathrm{ZrO}_{2} \text { Multi } \\
\text { Translucent ** }\end{array}$} & top & $5 Y$ & $>800$ & 49 & 3 & & \\
\hline \multirow{2}{*}{ ML5/3 2 b } & & middle & $3 Y / 5 Y$ & $>1150 />800$ & $40-49$ & 5 & 16 & 2 \\
\hline & & bottom & $3 Y$ & $>1150$ & 40 & 8 & & \\
\hline 3Y-A & $\begin{array}{c}\text { priti multidisc } \\
\text { opaque }^{* *}\end{array}$ & / & 3Y-A & $>1150$ & 35 & 16 & 16 & 2 \\
\hline $3 Y$ & $\begin{array}{l}\text { priti multidisc } \\
\text { translucent }\end{array}$ & / & $3 Y$ & $>1150$ & 40 & 16 & 16 & 2 \\
\hline $4 \mathrm{Y}$ & $\begin{array}{l}\text { experimental } \\
\text { material } 3^{* *}\end{array}$ & / & $4 Y$ & $>1150$ & 45 & 16 & 16 & 2 \\
\hline $4 \mathrm{Y} / 5 \mathrm{Y}$ & $\begin{array}{l}\text { experimental } \\
\text { material } 2 * *\end{array}$ & / & $4 \mathrm{Y} / 5 \mathrm{Y}$ & $>1150 />800$ & $45 / 49$ & 16 & 16 & 2 \\
\hline $5 Y$ & $\begin{array}{l}\text { experimental } \\
\text { material } 1^{* *}\end{array}$ & / & $5 Y$ & $>800$ & 49 & 16 & 16 & 2 \\
\hline
\end{tabular}

a: above position within zirconia blank; b: bottom position within zirconia blank; *: Ivoclar Vivadent GmbH, Ellwangen, D; **: Pritidenta, Leinfelden-Echterdingen, D; sintering with ht speed, Mihm-Vogt, Stutensee-Blankenloch, D. 1: heat-up rate $20-900{ }^{\circ} \mathrm{C}: 10^{\circ} \mathrm{C} / \mathrm{min}$, holding time $30 \mathrm{~min}$ at $900{ }^{\circ} \mathrm{C}$, heat-up rate $900-1500{ }^{\circ} \mathrm{C}: 3,3{ }^{\circ} \mathrm{C} / \mathrm{min}$, holding time $120 \mathrm{~min}$ at $1500{ }^{\circ} \mathrm{C}$, cooling rate $1500-900{ }^{\circ} \mathrm{C}: 10^{\circ} \mathrm{C} / \mathrm{min}$, cooling rate $900-300{ }^{\circ} \mathrm{C}: 8,3{ }^{\circ} \mathrm{C} / \mathrm{min}$. 2: heat-up rate: $10^{\circ} \mathrm{C} / \mathrm{min}$, holding time $120 \mathrm{~min}$ at $1450{ }^{\circ} \mathrm{C}$, cooling rate: $10^{\circ} \mathrm{C} / \mathrm{min}$.

\section{Results}

After TCML, two of the FPDs in group 5Y showed lateral cracks at the premolar crown. These two FPDs were not subjected to fracture force testing (5Y/TCML $n=6)$. All the other investigated FPDs survived TCML without ascertainable damages. Minimal or no wear was observed in the occlusal contact areas of the FPDs. The mean fracture force after $24 \mathrm{~h}$ water storage varied between $803.8 \pm 171.7 \mathrm{~N}(5 \mathrm{Y})$ and $1474.1 \pm 193.0 \mathrm{~N}$ (3Y) (Table 2). The mean fracture force after TCML varied between $713.5 \pm 190.9 \mathrm{~N}(5 \mathrm{Y})$ and $1337.4 \pm 205.6 \mathrm{~N}$ (3Y). The one-way ANOVA revealed significant differences between the groups before as well as after TCML $(p=0.000)$. The Bonferroni comparison of fracture force showed individual significant differences between the groups $(p \leq 0.039)$. No significant $(p=0.018)$ correlation between the obtained fracture force and flexural strength of the investigated materials was found. The failures of all the investigated FPDs were located in the connector between tooth 25 and tooth 26 (Figure 1).

A detailed fractographic analysis showed that the fractures originated from individual points at the bottom of the connectors (Figure 2). Thus, as expected, the areas with the highest tensile stresses were the starting points of the failure. The crack propagation always occurred in the occlusal direction and was usually characterized by a compression zone below the occlusal surface. 


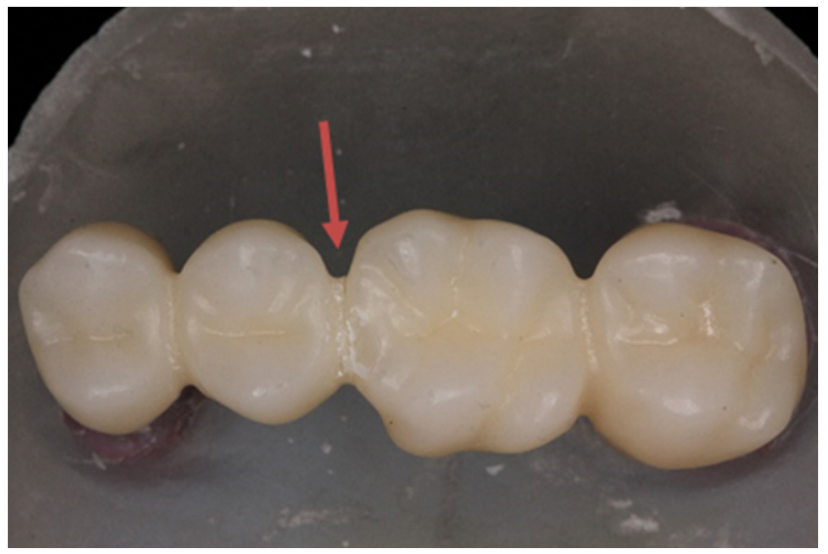

Figure 1. Exemplary picture of prevailing failure mode by cracking in the connector area (arrow).

3Y/ baseline

4Y/5Y / baseline
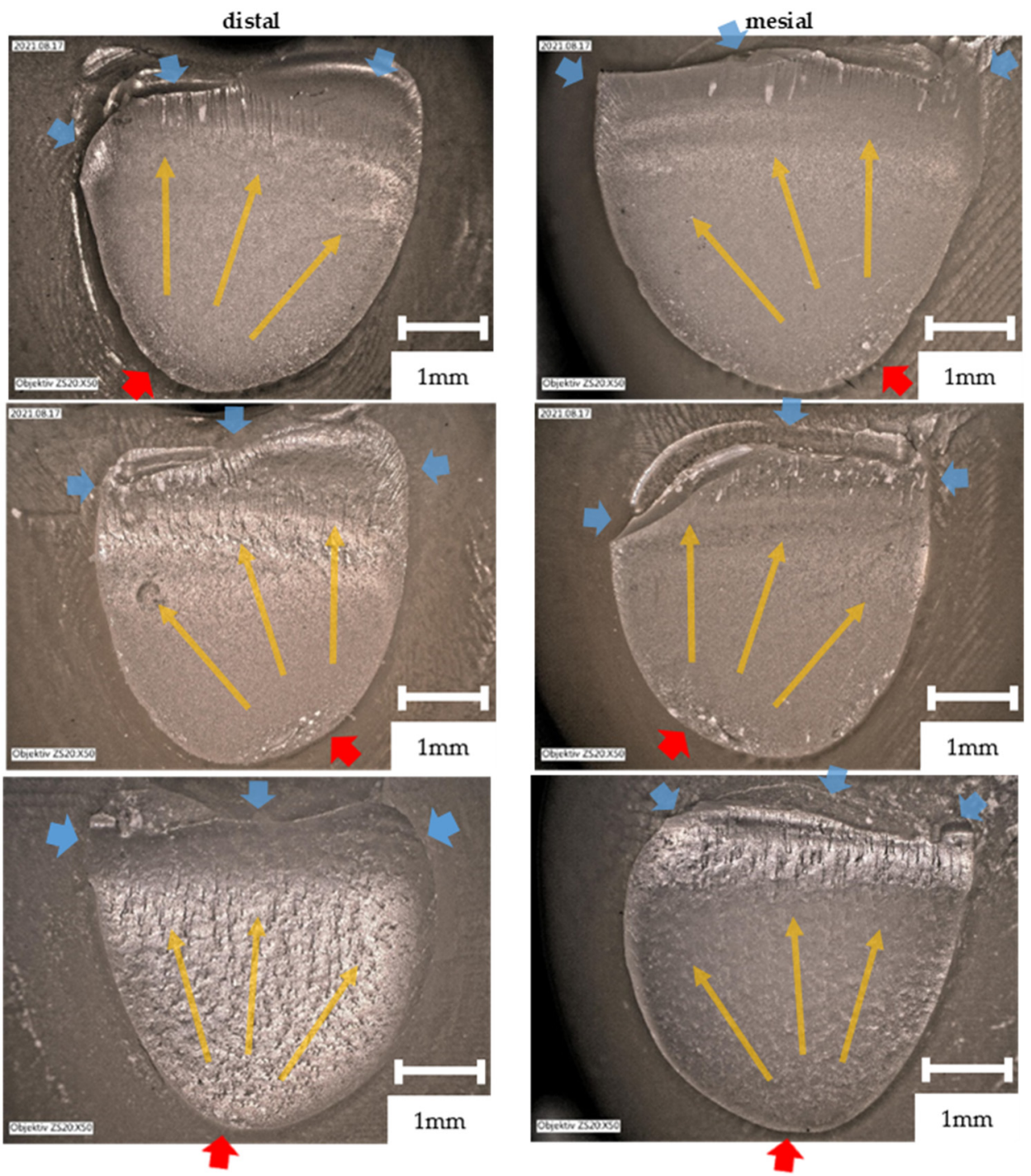

Figure 2. Exemplary fracture surfaces (mesial/distal aspect; cross section approx. $12 \mathrm{~mm}^{2}$; EOS 60D with macro lens EF-S 60mm 1:2.8 and macro ring lite MR-14EX, Canon, Öta, J): crack initiation at defects in the connector area on the gingival side of the restoration (red arrows), crack propagation to the top (yellow arrows) and to the sides of the connector, occlusal fracture edge (blue arrows). 
Table 2. Fracture force $[\mathrm{N}]$ (mean \pm standard deviation).

\begin{tabular}{|c|c|c|}
\hline Group & $\begin{array}{c}\text { Baseline } \\
\left(24 \mathrm{~h} \text { Waterstorage at } 37^{\circ} \mathrm{C}\right)\end{array}$ & $\begin{array}{c}\text { TCML } \\
\text { (Thermocyclng and } \\
\text { Mechanical Loading) }\end{array}$ \\
\hline ML5/31 a & $1140 \pm 177$ & $1140 \pm 125^{\mathrm{A}}$ \\
\hline ML5/3 $1 \mathrm{~b}$ & $1003 \pm 143^{a}$ & $1106 \pm 106^{B}$ \\
\hline ML5/3 2 a & $1237 \pm 408^{b}$ & $970 \pm 84^{C}$ \\
\hline ML5/3 $2 \mathrm{~b}$ & $1180 \pm 340$ & $1154 \pm 233^{\mathrm{D}}$ \\
\hline 3Y-A & $1333 \pm 203^{c}$ & $1184 \pm 181^{\mathrm{E}}$ \\
\hline $3 Y$ & $1474 \pm 193^{a, d, e, f}$ & $1337 \pm 206^{C, F, G}$ \\
\hline $4 Y$ & $959 \pm 89^{\mathrm{e}}$ & $913 \pm 106^{\mathrm{G}}$ \\
\hline $4 \mathrm{Y} / 5 \mathrm{Y}$ & $1080 \pm 205^{\mathrm{f}}$ & $1112 \pm 152^{\mathrm{H}}$ \\
\hline $5 Y$ & $804 \pm 172^{b, c, d}$ & $714 \pm 191^{\mathrm{A}, \mathrm{B}, \mathrm{D}, \mathrm{E}, \mathrm{F}, \mathrm{H}}$ \\
\hline
\end{tabular}

\section{Discussion}

The hypothesis, that the in vitro performance and fracture force of 4-unit FPDs is influenced by the $\mathrm{Y}_{2} \mathrm{O}_{3}$-content (3Y-TZP, 4 Y-TZP, 5Y-TZP), was confirmed. Significant $(p \leq 0.001)$ differences between the fracture force of several groups were found (Table 2).

The hypothesis, that the in vitro performance and fracture force of 4-unit FPDs is influenced by the $\mathrm{Al}_{2} \mathrm{O}_{3}$-content (3Y-TZP, 3Y-TZP-A), was not confirmed. The determined differences were only insignificant $(p=1.000)$.

The hypothesis, that the in vitro performance and fracture force of 4-unit FPDs is influenced by the composition in terms of a uniform mixture of 4Y-TZP and 5Y-TZP, was confirmed. Significant differences $(p \leq 0.039)$ in the fracture force towards the other test groups were found.

The hypothesis, that 4-unit FPDs made from different layers of multilayer blanks show individual in vitro performance, was not confirmed. For the groups that were milled from different positions of one blank type, variations in the fracture force were not significant $(p=1.000)$ after either 24-h water storage or thermocycling and mechanical loading.

The highest masticatory forces occur in the area of the second premolar and the first molar. Maximum bite force values of approximately $500 \mathrm{~N}$ are to be expected [16]. In bruxism patients, the occurring bite forces can exceed $1000 \mathrm{~N}$ in individual cases [17]. While all the other materials show sufficient stability, the fracture force of $5 \mathrm{Y}$ obtained in this study is in a range that argues against the application for wide-span FPDs in the posterior region. A comparison of the mean fracture force after water storage and after TCML did not show any significant differences. For most of the materials investigated, only tendencies towards slightly reduced fracture force after TCML could be observed. Yet, in groups $4 \mathrm{Y} / 5 \mathrm{Y}$ and ML5/3 $1 \mathrm{~b}$, TCML resulted in a slightly higher mean fracture force compared to the values after $24 \mathrm{~h}$ water storage, confirming a strengthening effect of TCML on 3Y-TZP $[9,18]$. An explanation for this effect might be a superficial $t-m$ phase transformation in 3Y-TZP fractions or contingently in 4Y-TZP fractions but not in 5Y-TZP [19]. This could cause compressive stresses in superficial areas of the restorations that counteract crack propagation [20]. In contrast, a recent study on zirconia with varying yttria content described a phase transformation from monoclinic to tetragonal as the result of mechanical stresses [21]. Apart from the martensitic phase transformation as a strengthening mechanism in zirconia, ferro-elastic domain switching is also described as a toughening effect caused by the reorientation of tetragonal zirconia crystalline domains. This may occur in materials that exhibit no transformation to the monoclinic form as a result of mechanical stress [22]. Irrespective of this, differences in the fracture force before and after TCML may also be attributed to the weakening of the luting material or impairment of adhesive bond strength $[23,24]$.

As expected, the highest fracture force was found for $3 \mathrm{Y}$ and $3 \mathrm{Y}-\mathrm{A}$, for which the manufacturers also specify high flexural strength. Further, the lowest fracture force was 
determined for 5 Y. For this material, the manufacturer states the lowest flexural strength of all materials investigated. Yet, regarding all the investigated materials, no correlation between the reported flexural strength and the determined fracture force was found. It seems that, for high strength ceramics and especially for wide-span restorations, the strength values behave in the sense of a Weibull distribution [25]. The fracture force of restorations depends on the presence of critical defects from which cracks may originate and is, therefore, not normally distributed. Such defects can be caused during the manufacturing process. Therefore, adequate polishing of restoration surfaces is essential [26,27] It must be clearly noted here that flexural strength was not measured as part of this study but derived from the information provided by the respective manufacturers.

An important aspect on the subject of multilayer zirconia blanks is the sometimes vague nomenclature used by manufacturers. On the one hand, color-gradient blanks are offered, where only the coloration varies within the blank. On the other hand, there are strength-gradient blanks, such as the ones that were investigated in this study, in which actually different zirconia types with varying yttria content are layered. In view of the fundamentally different materials, a clear distinction must be made here [28]. Regarding the mechanical properties resulting from the different depths of cut in multilayer zirconia blanks, it has already been reported that the fracture performance of single crowns determined after fatigue loading varies depending on the milling position [15]. However, different mechanical properties at the investigated milling positions in multilayer materials were not always found. In a recently published study, a similar wear behavior was determined for different layers of a multilayer material [29]. A previous study found no significant difference in the fracture force of 3-unit FPDs milled from different positions in multilayer blanks [13]. The results of this study support these findings when considering 4-unit FPDs.

The fracture force measurements in this study investigated the load exerted by an antagonistic steel ball that was set occlusally in the middle connector area between the two pontics. The photographs of the surfaces formed along the fracture clefts allow further conclusions to be drawn about the fracture formation. It appears that the fractures originated from individual points at the lower edge of the connectors (Figure 2; red arrows). From there, the cracks move further occlusally and to the sides of the connector with a predominantly vertical course (Figure 2; yellow arrows). In the occlusal part, under the influence of compression by the steel ball, the course of the fracture edge shifts in a horizontal direction and ends with an offset towards the lower parts of the fracture gap (Figure 2; blue arrows). The recommended connector cross-sections for three-unit zirconia bridges are $7 \mathrm{~mm}^{2}$ (anterior region) or $9 \mathrm{~mm}^{2}$ (posterior region) and $12 \mathrm{~mm}^{2}$ for multi-unit bridges. The height of the connector cross-section has a greater impact on the stability of the restoration than its width. Other important aspects of the connector design are that sharp edges should be avoided all around, and in particular on the gingival side a rounded design with the largest possible radii is aimed for [30]. The occurrence of this fracture pattern may have been favored by the simulation of the periodontal structures using the polyether coating of the artificial tooth roots. Thus, the abutment teeth could tilt towards each other as a result of loading in the central connector area, similar to the situation that is expected in vivo. The approach of using a polyether coating of abutment teeth in a chewing simulation is not sufficient to fully simulate periodontal resilience, but it can help to avoid the overestimation of mechanical strength in in vitro tests [31].

Especially when investigating all-ceramic restorations, additional thermocycling during the chewing simulation seems to play an important role in ensuring that the fracture force is not assumed to be too high [32]. The applied TCML parameters were chosen as they have already been successfully applied in previous in vitro studies $[9,33]$. These test parameters seem to be suitable to simulate the clinical application of the restorations for about 5 years of wear time [34]. The FPDs were adhesively luted to the PMMA abutment teeth. Conventional cementation can achieve clinical long-term success of zirconia FPDs. Yet, resin bonding is recommended as higher success rates are suggested [35]. Compared to adhesively luted zirconia FPDs, loss of retention seems to appear more frequent with 
conventionally cemented zirconia FPDs [36]. Unfortunately, there is still no standardized protocol for the adhesive cementation of zirconia restorations [37]. Due to their mechanical properties, 5Y-TZP materials, which are specified by the manufacturers with flexural strength in the order of $800 \mathrm{MPa}$, occupy an intermediate position between the conventional zirconia materials and high-strength glass-ceramic materials, such as lithium disilicate [9]. Especially, such less stable zirconia materials may have benefited from adhesive luting in this study.

\title{
5. Conclusions
}

- $\quad$ Zirconia restorative materials (3Y-TZP-A, 3Y-TZP, 4Y-TZP, 5Y-TZP, mixed 4Y-TZP/5Y$\mathrm{TZP}$, multilayer 3Y-TZP/5Y-TZP) show individual in vitro performance and fracture force depending on their composition.

- Investigated 5Y-TZP does not appear to be suitable for the fabrication of wide-span molar FPDs.

- $\quad$ Even with wide-span 4-unit FPDs, the milling position within multilayer blanks seems to have only minor effects on the mechanical properties of the fabricated restorations.

- For the fracture force of high-strength zirconia restorations, there seems to be no general correlation to the flexural strength of the respective materials.

\begin{abstract}
Author Contributions: Conceptualization: T.S., M.R.; methodology: M.R.; software, T.S., A.S. and M.R.; validation, T.S., A.S. and C.H.; formal analysis, T.S. and M.R.; investigation, A.S. and M.R.; resources, M.R.; data curation, T.S. and M.R.; writing-original draft preparation, T.S.; writingreview and editing, T.S., A.S., C.H., M.R.; visualization, T.S. and A.S.; supervision, T.S. and M.R.; project administration, T.S. and M.R. All authors have read and agreed to the published version of the manuscript.
\end{abstract}

Funding: This research received no external funding.

Institutional Review Board Statement: Not applicable.

Informed Consent Statement: Not applicable.

Data Availability Statement: The data presented in this study are available within the article.

Acknowledgments: The authors would like to thank Ivoclar Vivadent GmbH (Ellwangen, D) and Pritidenta (Leinfelden-Echterdingen, D) for providing the materials.

Conflicts of Interest: The authors declare no conflict of interest.

\section{References}

1. Mazza, L.C.; Lemos, C.A.A.; Pesqueira, A.A.; Pellizzer, E.P. Survival and complications of monolithic ceramic for tooth-supported fixed dental prostheses: A systematic review and meta-analysis. J. Prosthet. Dent. 2021. [CrossRef] [PubMed]

2. Silva, L.H.d.; de LIima, E.; Miranda, R.B.d.P.; Favero, S.S.; Lohbauer, U.; Cesar, P.F. Dental ceramics: A review of new materials and processing methods. Braz. Oral Res. 2017, 31. [CrossRef] [PubMed]

3. Laumbacher, H.; Strasser, T.; Knüttel, H.; Rosentritt, M. Long-term clinical performance and complications of zirconia-based tooth- and implant-supported fixed prosthodontic restorations: A summary of systematic reviews. J. Dent. 2021, 111, 103723. [CrossRef] [PubMed]

4. Saravi, B.; Vollmer, A.; Hartmann, M.; Lang, G.; Kohal, R.-J.; Boeker, M.; Patzelt, S.B.M. Clinical Performance of CAD/CAM All-Ceramic Tooth-Supported Fixed Dental Prostheses: A Systematic Review and Meta-Analysis. Materials 2021, $14,2672$. [CrossRef] [PubMed]

5. Poggio, C.E.; Ercoli, C.; Rispoli, L.; Maiorana, C.; Esposito, M. Metal-free materials for fixed prosthodontic restorations. Cochrane Database Syst. Rev. 2017, 12. [CrossRef] [PubMed]

6. Tabatabaian, F. Color Aspect of Monolithic Zirconia Restorations: A Review of the Literature. J. Prosthodont. 2019, 28, 276-287. [CrossRef]

7. Solá-Ruíz, M.F.; Rico-Coderch, A.; Montiel-Company, J.M.; Fons-Badal, C.; Verdejo-Solá, B.; Agustín-Panadero, R. Influence of the chemical composition of monolithic zirconia on its optical and mechanical properties. Systematic review and meta-regression. J. Prosthodont. Res. 2021. [CrossRef]

8. Fathy, S.M.; Al-Zordk, W.; Grawish, M.E.; Swain, M.V. Flexural strength and translucency characterization of aesthetic monolithic zirconia and relevance to clinical indications: A systematic review. Dent. Mater. 2021, 37, 711-730. [CrossRef] 
9. Rosentritt, M.; Preis, V.; Behr, M.; Strasser, T. Fatigue and wear behaviour of zirconia materials. J. Mech. Behav. Biomed. Mater. 2020, 110, 103970. [CrossRef]

10. Jerman, E.; Lümkemann, N.; Eichberger, M.; Hampe, R.; Stawarczyk, B. Impact of varying step-stress protocols on the fatigue behavior of 3Y-TZP, 4Y-TZP and 5Y-TZP ceramic. Dent. Mater. 2021, 37, 1073-1082. [CrossRef]

11. Stawarczyk, B.; Keul, C.; Eichberger, M.; Figge, D.; Edelhoff, D.; Lümkemann, N. Three generations of zirconia: From veneered to monolithic. Part I. Quintessence Int. 2017, 48, 369-380. [CrossRef] [PubMed]

12. Stawarczyk, B.; Keul, C.; Eichberger, M.; Figge, D.; Edelhoff, D.; Lümkemann, N. Three generations of zirconia: From veneered to monolithic. Part II. Quintessence Int. 2017, 48, 441-450. [CrossRef] [PubMed]

13. Rosentritt, M.; Preis, V.; Schmid, A.; Strasser, T. Multilayer zirconia: Influence of positioning within blank and sintering conditions on the in vitro performance of 3-unit fixed partial dentures. J. Prosthet. Dent. 2020, 127, 141-145. [CrossRef] [PubMed]

14. Kaizer, M.R.; Kolakarnprasert, N.; Rodrigues, C.; Chai, H.; Zhang, Y. Probing the interfacial strength of novel multi-layer zirconias. Dent. Mater. 2020, 36, 60-67. [CrossRef]

15. Li, X.; Wang, Q.; Qiu, X.; Zhao, B. Effect of different CAD/CAM cutting depths on the post-fatigue load-bearing capacity of novel multilayer zirconia restorations. J. Dent. 2021, 111, 103709. [CrossRef]

16. Linderholm, H.; Wennström, A. Isometric Bite Force and its Relation to General Muscle Forge and Body Build. Acta Odontol. Scand. 1970, 28, 679-689. [CrossRef]

17. Gibbs, C.H.; Mahan, P.E.; Mauderli, A.; Lundeen, H.C.; Walsh, E.K. Limits of human bite strength. J. Prosthet. Dent. 1986, 56, 226-229. [CrossRef]

18. Lümkemann, N.; Stawarczyk, B. Impact of hydrothermal aging on the light transmittance and flexural strength of colored yttria-stabilized zirconia materials of different formulations. J. Prosthet. Dent. 2021, 125, 518-526. [CrossRef]

19. Lughi, V.; Sergo, V. Low temperature degradation-aging-of zirconia: A critical review of the relevant aspects in dentistry. Dent. Mater. 2010, 26, 807-820. [CrossRef]

20. Virkar, A.V.; Huang, J.L.W.; Cutler, R.A. Strengthening of Oxide Ceramics by Transformation-Induced Stress. J. Am. Ceram. Soc. 1987, 70, 164-170. [CrossRef]

21. Wertz, M.; Fuchs, F.; Hoelzig, H.; Wertz, J.M.; Kloess, G.; Hahnel, S.; Rosentritt, M.; Koenig, A. The Influence of Surface Preparation, Chewing Simulation, and Thermal Cycling on the Phase Composition of Dental Zirconia. Materials 2021, 14, 2133. [CrossRef] [PubMed]

22. Virkar, A.V.; Matsumoto, R.L.K. Ferroelastic Domain Switching as a Toughening Mechanism in Tetragonal Zirconia. J. Am. Ceram. Soc. 1986, 69, C-224-C-226. [CrossRef]

23. Ülker, M.; Özcan, M.; Şengün, A.; Özer, F.; Belli, S. Effect of artificial aging regimens on the performance of self-etching adhesives. J. Biomed. Mater. Res. 2010, 93, 175-184. [CrossRef] [PubMed]

24. Behr, M.; Proff, P.; Kolbeck, C.; Langrieger, S.; Kunze, J.; Handel, G.; Rosentritt, M. The bond strength of the resin-to-zirconia interface using different bonding concepts. J. Mech. Behav. Biomed. Mater. 2011, 4, 2-8. [CrossRef] [PubMed]

25. Quinn, J.B.; Quinn, G.D. A practical and systematic review of Weibull statistics for reporting strengths of dental materials. Dent. Mater. 2010, 26, 135-147. [CrossRef] [PubMed]

26. de Carvalho, I.H.G.; da Silva, N.R.; Vila-Nova, T.E.L.; de Fatima Dantas Almeida, L.; Veríssimo, A.H.; de Melo, R.M.; Zhang, Y.; de Assunção e Souza, R.O. Effect of finishing/polishing techniques and aging on topography, C. albicans adherence, and flexural strength of ultra-translucent zirconia: An in situ study. Clin. Oral Investig. 2021, 26, 889-900. [CrossRef]

27. Lee, J.-Y.; Jang, G.-W.; Park, I.-I.; Heo, Y.-R.; Son, M.-K. The effects of surface grinding and polishing on the phase transformation and flexural strength of zirconia. J. Adv. Prosthodont. 2019, 11, 1. [CrossRef]

28. Michailova, M.; Elsayed, A.; Fabel, G.; Edelhoff, D.; Zylla, I.-M.; Stawarczyk, B. Comparison between novel strength-gradient and color-gradient multilayered zirconia using conventional and high-speed sintering. J. Mech. Behav. Biomed. Mater. 2020, $111,103977$. [CrossRef]

29. Vardhaman, S.; Borba, M.; Kaizer, M.R.; Kim, D.; Zhang, Y. Wear behavior and microstructural characterization of translucent multilayer zirconia. Dent. Mater. 2020, 36, 1407-1417. [CrossRef]

30. Hafezeqoran, A.; Koodaryan, R.; Hemmati, Y.; Akbarzadeh, A. Effect of connector size and design on the fracture resistance of monolithic zirconia fixed dental prosthesis. J. Dent. Res. 2020, 14, 218-222. [CrossRef]

31. Rosentritt, M.; Behr, M.; Scharnagl, P.; Handel, G.; Kolbeck, C. Influence of resilient support of abutment teeth on fracture resistance of all-ceramic fixed partial dentures: An in vitro study. Int. J. Prosthodont. 2011, 24, 465-468. [PubMed]

32. Rosentritt, M.; Behr, M.; Gebhard, R.; Handel, G. Influence of stress simulation parameters on the fracture strength of all-ceramic fixed-partial dentures. Dent. Mater. 2006, 22, 176-182. [CrossRef]

33. Preis, V.; Hahnel, S.; Behr, M.; Rosentritt, M. In vitro performance and fracture resistance of novel CAD/CAM ceramic molar crowns loaded on implants and human teeth. J. Adv. Prosthodont. 2018, 10, 300. [CrossRef] [PubMed]

34. Behr, M.; Hindelang, U.; Rosentritt, M.; Lang, R.; Handel, G. Comparison of failure rates of adhesive-fixed partial dentures for in vivo and in vitro studies. Clin. Oral Investig. 2000, 4, 25-30. [CrossRef] [PubMed]

35. Blatz, M.B.; Vonderheide, M.; Conejo, J. The Effect of Resin Bonding on Long-Term Success of High-Strength Ceramics. J. Dent. Res. 2018, 97, 132-139. [CrossRef] [PubMed] 
36. Le, M.; Papia, E.; Larsson, C. The clinical success of tooth- and implant-supported zirconia-based fixed dental prostheses. A systematic review. J. Oral Rehabil. 2015, 42, 467-480. [CrossRef] [PubMed]

37. Comino-Garayoa, R.; Peláez, J.; Tobar, C.; Rodríguez, V.; Suárez, M.J. Adhesion to Zirconia: A Systematic Review of Surface Pretreatments and Resin Cements. Materials 2021, 14, 2751. [CrossRef] 